\title{
THE TIME-SPACE APPROACH IN THE ANALYSIS OF TRAFFIC SAFETY ON RURAL ROAD
}

MSc Svetlana Bačkalić, assistant, University of Novi Sad, Faculty of technical sciences, email: basic@uns.ac.rs

MSc Boško Matović, training assistant, University of Novi Sad, Faculty of technical sciences, e-mail: boskom@uns.ac.rs

MSc Anja Bašić, research assistant, University of Novi Sad, Faculty of technical sciences, email: anjuskab@gmail.com

\section{Abstract}

Analysis of the traffic safety factors in some region (road, section of road, road's kilometer) is an important task in the field of traffic safety. It is necessary to constantly monitor, analyze, compare traffic safety situation in order to develop and improve measures for increasing the level of traffic safety. The first part of each analysis is finding of positions of traffic accidents and its casualties, in other words it is necessary to find its coordinates in the space-time coordinate system.

This paper shows results of the descriptive statistical analysis of traffic accidents frequency on the rural road for the period 2005-2011. It will be point out advantages and disadvantages of this approach and also it will be suggested a new individual approach for determinate the mean time between consecutive traffic accidents.

Keywords: descriptive analysis, traffic safety, accident

\section{INTRODUCTION}

Road safety is one of the main issues in transportation. It is important to emphasize that road safety is a global problem. Global status report on road safety 2013 shows that 1,24 million people were killed on the world's roads in 2010 [1]. This number is unacceptably high, especially if we add a number of injured which is as many as 50 million every year [2]. One of the aims in the road safety research is to find ways to reduce the number of road accidents and their severity.

Crash frequency modeling is a subject of traffic safety research for many decades. Many papers, studies in this field show that the number of road 
accidents can be modeled by using various techniques to identify the relationship of different variables with number of road accidents.

In earlier research from the aspect temporal analysis of road accidents two approaches were singled out. One of them is collective, which analyze crash frequency over a long period of time $[3,4,5]$, and another is individual, which determines estimation of real time crash likelihood $[6,7,8,20]$.

Modeling traffic accident is not easy work, and researchers are faced with many problems. One of them is absence of individual vehicle crashes information that would help improve the identification of cause and effect relationships with individual vehicle crashes. Also in many middle-income countries data basis of traffic accident is very weak and incomplete. Because of this researchers do not have choice. They try to understand the factors that affect the frequency of crashes (the number of crashes occurring in some geographical space (roadway segment or intersection)) over some specified time period [9]. Many authors in earlier research tried to establish relationship between factors which have a different influence on frequency of traffic accident as hourly traffic flow [10,11], weather conditions [12,13,14], road geometric (degree of horizontal curvature, lane, shoulder and median widths, urban, rural, and the section's length) [15]. The number of road accidents can be modeled by using various techniques to identify the relationship of different variables with number of road accidents. Lord and Mannering gave a detailed review of the key issues associated with crash-frequency data as well as the advantages and disadvantages of the various methodological approaches that researchers have used to address these problems. They point out also a problem with characteristic of crash-frequency data as over-dispersion, under-dispersion, time-varying explanatory variables, temporal and spatial correlation, low sample-mean and small sample size, injury-severity and crash-type correlation, under-reporting, omitted-variables bias, endogenous variables, functional form, fixed parameters [9].

This paper shows the result of collective approach (temporal analysis per hour, day, and month) and results of the mean time between two consecutive traffic accidents which is some kind of individual approach.

\section{METHOD}

In this paper the basic results for the main rural road in Province of Vojvodina are presented. This road is made of 20 sections of total length $255,113 \mathrm{~km}$. The sections represent parts of the road network between two 
consecutive traffic nodes and are used to provide for continuous and unobstructed traffic flows [16]. This road sections is specific by the structure, volume of traffic accidents, road equipment, road environment, road characteristics etc.

Period of analysis is from 2005 to 2011, when were occurred 1010 traffic accidents on the observed road. All the traffic accidents have been allocated according time of occurrence (year/month/hour) and location on the road (kilometer/meter), which provides us with the spatial-temporal distribution of traffic accidents per section. This kind of basic descriptive statistic is a first step in traffic safety analysis. This paper shows possibility of applying the basic principles of the reliability theory for calculating the mean time between two consecutive accidents.

\section{RESULTS}

Trend line of traffic accidents shows that in the last three year the number of traffic accident falling down (Figure 1). Statistical parameters which are shown in Table 1 provide a more comprehensive picture regarding the trend of traffic accidents. Beside parameters that show the average number of traffic accidents there are also parameters which indicate the dispersion of accidents for this period of time, as well as skewness (degree of asymmetry of a distribution around its mean.) and kurtosis (measure of flatness of the distribution). Mean of accidents for this period is 144 , while the standard deviation of the total number of accidents on each year than the average value is 40 , which indicates a significant dispersion of data.

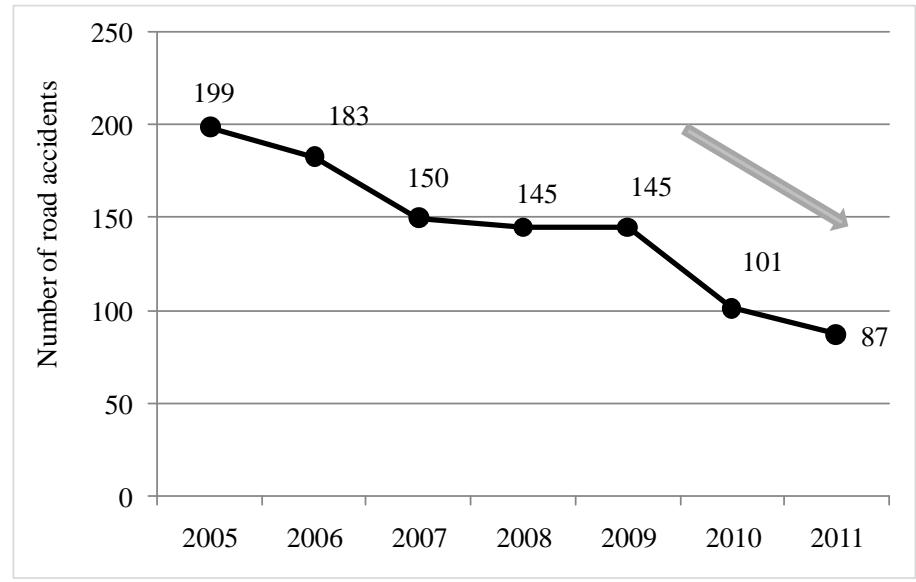

Figure 1. Number of road accidents per year 
ROMANIAN JOURNAL

OF TRANSPORT INFRASTRUCTURE

Svetlana Bačkalić, Boško Matović, Anja Bašić

The time-space approach in the analysis of traffic safety on rural road

Table 1. Parameters of descriptive statistic for road accidents, period 2005-2011

\begin{tabular}{|l|c|l|l|c|}
\hline \multicolumn{1}{|c|}{ Descriptive } & Statistic & & \multicolumn{1}{c|}{ Descriptive } & Statistic \\
\cline { 1 - 2 } Mean & 144 & & Maximum & 199 \\
\cline { 1 - 2 } Median & 145 & & Range & 112 \\
\cline { 1 - 1 } Variance & 1614 & & Interquartile Range & 82 \\
\hline Std. Deviation & 40 & & Skewness & 0 \\
\hline Minimum & 87 & & Kurtosis & -1 \\
\hline
\end{tabular}

The data are symmetrically distributed around the mean value because the degree of asymmetry (skewness) has a zero value. Kurtosis has a value of -1 , which indicates a relatively flat distribution than the normal curve.

If we look the distribution of accidents on each year by hour of day, there is a certain appearance of extreme values (outliers), but this is a relatively small sample size, so these values can be misleading. The largest number of accidents occurs in the morning hour between 8 and 9 am, when people commute to the work, second interval is between 2 to $5 \mathrm{pm}$ when the typical purpose of the trip is return back from work, and also there is a pick in the evening at $5 \mathrm{pm}$ and 19 pm when people commute because of some kind of social activities or recreation (Figure 2).

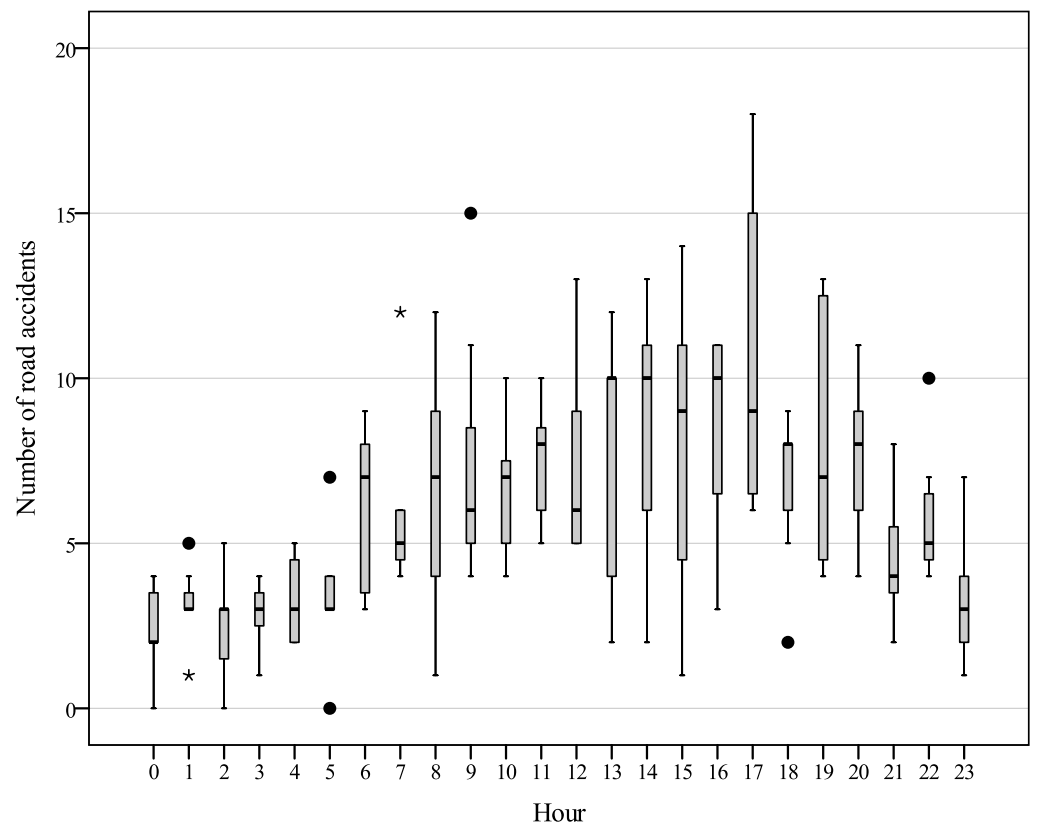

Figure 2. Number of road accidents on each year by hour of day 
The variation in number of road accidents occurring on different days of the week on each year, shows that the largest number of accidents on this road occurred on Wednesdays, where the accident slightly asymmetrical. During the weekend days, on Saturday occurred more accidents than on Sunday (Figure 3).

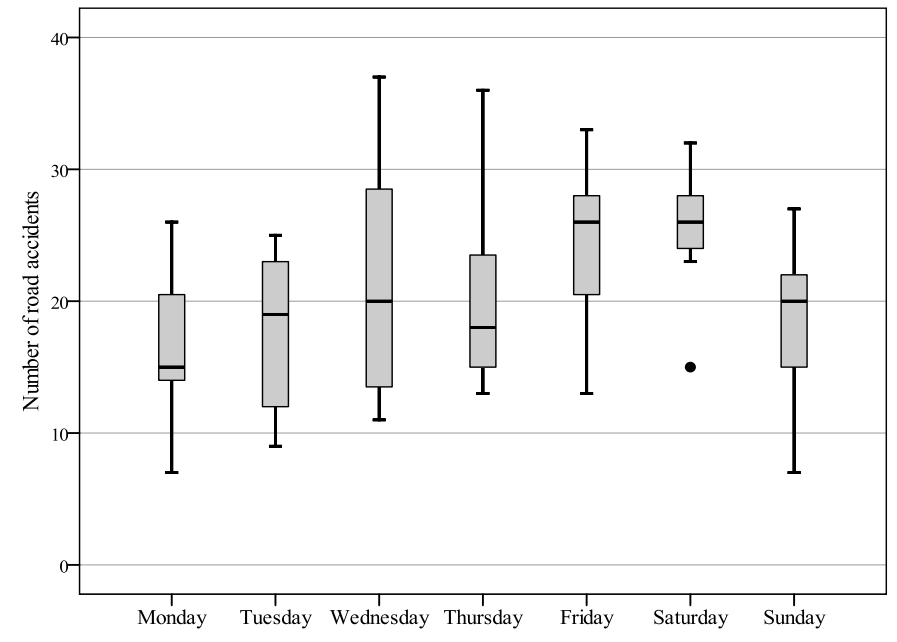

Figure 3. Number of road accidents on each year by day of week

Analysis of accidents frequency on each year by month of the year shows that the end of the summer and beginning of autumn are the most critical period of year. October is the month with the greatest number of road accidents. Also in March, it is observed increasing in the number of accidents, which is associated with human activities and their exposure to road traffic accidents (Figure 4).

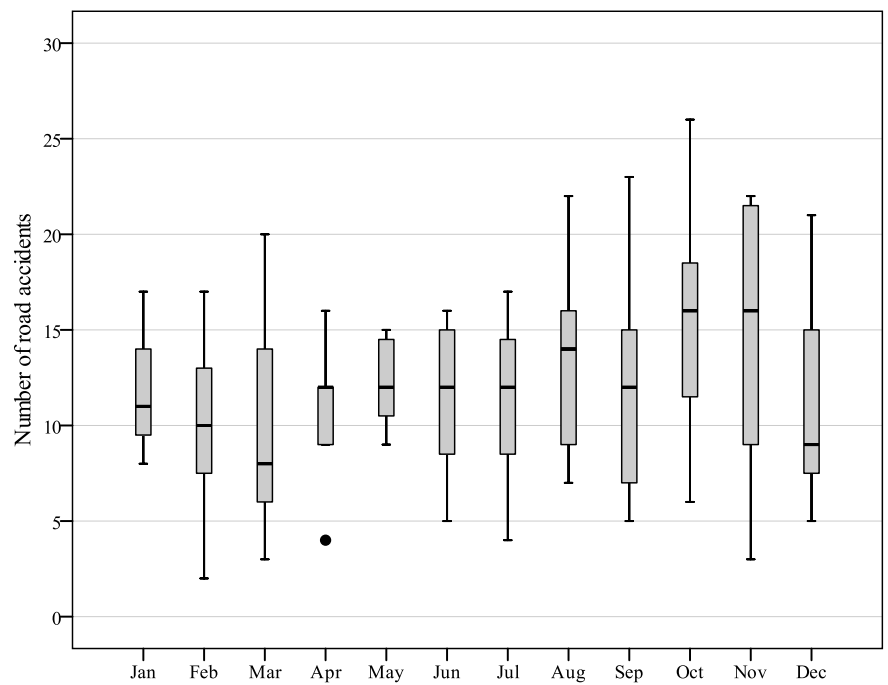

Figure 4. Number of road accidents on each year by month of the year 
ROMANIAN JOURNAL

OF TRANSPORT INFRASTRUCTURE

Svetlana Bačkalić, Boško Matović, Anja Bašić

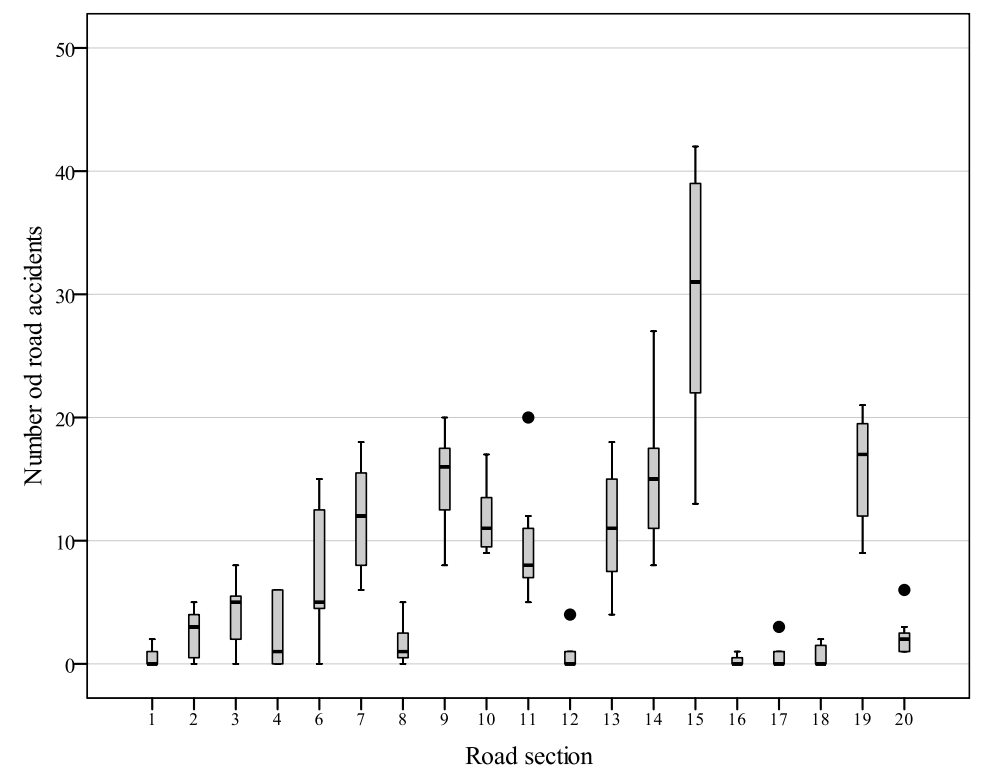

Figure 5. Number of road accidents on each year by road sections

Comparative analysis between road sections shows that the section 15 is the most dangerous section and it is followed by sections 14, 19, 9, while and the most safety are the section 5 (without accident), 16, 1, 17, 18, 12 (Figure 5).

Because stream of events has Poisson's distribution, then the time between the occurrences of two accidents can be described with an exponential distribution. Therefore, it has been adopted that all the empirical distributions of the duration of the period without accidents can be replaced with the corresponding exponential distributions. The parameters of road reliability are then calculated from a temporal aspect according to the forms of the technical systems reliability theory $[17,18,19]$ (Formulas 1-4).

The density function of the distribution of the time between two accidents $f(t)$ represents a measure of the speed of the accident's occurrence[8, 20]. The function of accident distribution density for the $i$-th section is:

$f_{i}(t)=\lambda_{i} e^{-\lambda_{i} t}$

where is: $\lambda \mathrm{i}>0, \mathrm{t} \geq 0$;

$\mathrm{t}$ is a time;

$\lambda$ is a distribution parameter.

Distribution function $F(t)$ of the random variable $T$ (the time between two accidents), is equal to the probability that an accident will occur before the 
moment $t$. This function is also called the function of unreliability. The distribution function of the time between two accidents on the $i$-th section unreliability function of the $i$-th section is:

$\mathrm{F}_{\mathrm{i}}(\mathrm{t})=\int_{0}^{\mathrm{t}} \mathrm{f}_{\mathrm{i}}(\mathrm{t}) \mathrm{dt}=\int_{0}^{\mathrm{t}} \lambda_{\mathrm{i}} \mathrm{e}^{-\lambda_{\mathrm{i}} \mathrm{t}} \mathrm{dt}=1-\mathrm{e}^{-\lambda_{\mathrm{i}} \mathrm{t}}$

Using the unreliability function $F(t)$ we introduce the reliability function $R(t)$, as the probability of a time period without accidents until the moment $t$. The reliability function of the $i$-th section is:

$R_{i}(t)=1-F_{i}(t)=e^{-\lambda_{i} t}$

The mean time between two accidents $T_{0}$ is an important reliability parameter and it can be obtained as a mathematical expectation of the random variable $T$. The mean time between two consecutive accidents on the road is calculated according to the following form:

$T_{0 \mathrm{i}}(t)=\int_{0}^{\infty} R(t) d t=\int_{0}^{\infty} t f_{i}(t) d t=\int_{0}^{\infty} e^{-\lambda_{\mathrm{i}} t} d t=\frac{1}{\lambda_{\bar{i}}}$

Table 2. Parameters of the observed road and the corresponding main results of the time between two accident per section and road, period $t=365$ (days)

\begin{tabular}{|c|c|c|c|}
\hline Section & $\begin{array}{c}\text { Length } \\
(\mathbf{k m})\end{array}$ & $\begin{array}{c}\text { Observed } \\
\text { number of } \\
\text { accidents } \\
(\mathbf{2 0 0 5 - 2 0 1 1})\end{array}$ & $\boldsymbol{T}_{\boldsymbol{o}}(\boldsymbol{h})$ \\
\hline 1 & 0,333 & 4 & 13433,25 \\
\hline 2 & 0,931 & 17 & 3584,18 \\
\hline 3 & 33,000 & 28 & 2129,57 \\
\hline 4 & 6,639 & 19 & 2236,53 \\
\hline 5 & 4,668 & 0 & $\infty$ \\
\hline 6 & 5,491 & 54 & 1076,83 \\
\hline 7 & 36,265 & 83 & 727,04 \\
\hline 8 & 1,752 & 12 & 4673,25 \\
\hline 9 & 19,574 & 104 & 584,32 \\
\hline 10 & 15,996 & 83 & 730,20 \\
\hline 11 & 15,701 & 69 & 887,91 \\
\hline \hline
\end{tabular}


ROMANIAN JOURNAL

OF TRANSPORT INFRASTRUCTURE

Svetlana Bačkalić, Boško Matović, Anja Bašić

The time-space approach in the analysis of traffic safety on rural road

\begin{tabular}{|c|c|c|c|}
\hline 12 & 1,661 & 6 & 4567,25 \\
\hline 13 & 8,622 & 78 & 761,97 \\
\hline 14 & 34,030 & 107 & 567,40 \\
\hline 15 & 25,520 & 208 & 294,26 \\
\hline 16 & 5,296 & 2 & 27127,00 \\
\hline 17 & 2,033 & 5 & 5256,00 \\
\hline 18 & 1,251 & 5 & 8872,80 \\
\hline 19 & 28,672 & 110 & 535,87 \\
\hline 20 & 7,678 & 16 & 3580,56 \\
\hline road & $\mathbf{2 5 5 , 1 1 3}$ & $\mathbf{1 0 1 0}$ & $\mathbf{5 8 , 2 3}$ \\
\hline
\end{tabular}

Testing the model on these parameters, main results about the mean time between two accidents are shown in Table 2 .

By comparing the mean time between two accidents we may conclude that the section 15 is the most dangerous road section, because it has the shortest $\mathrm{T}_{0}$ and it is followed by section $19,14,9,7$, while the most safety sections according $\mathrm{T}_{0}$ are $5,16,1,18,17,8$. On observed road traffic accident happens every 58,23 hour.

\section{DISCUSSION}

Most models for traffic frequency analysis are actually count-data models which counts traffic accidents during some period of time. Duration model consider the time between crashes, as opposed to the frequency of crashes over some time period [9]. But it is important to point out that the crash frequency and time between crashes are obviously interrelated. In this paper we show how descriptive analysis can be a first part of analysis but if we have the small sample size for short period of analysis it is not very good for making some deep conclusions.

If we observe the trend line of traffic accidents for the period 2005-2011 on this road, it could be conclude decreasing trend of the traffic accidents (Figure 1). In order to perform a quality road safety assessment for this road it is necessary to find out influence of all possible circumstances that led to this trend, as well as influence of different traffic safety indicators which are based 
on the accidents consequences and relative indicators that take into account the exposure to traffic accidents.

This paper shows possibility to avoid problems with data and also monitor the traffic safety on the road network. The mean time between two consecutive traffic accidents is calculated by formulas of basic principle theory of reliability.

\section{CONCLUSION}

Modeling of traffic accidents and interpretation of the data can lead to better identification and understanding of traffic safety problems. This approach is very important for developing and evaluating appropriate road safety measures on section where the accident is usually occurring, on other words on section where the time between two accidents is short. This approach leads straight to the problematic sections. Road safety experts for analysis require large numbers of road accidents with different factors which have influence on it. The mean time between two consecutive traffic accidents as results of traffic safety analysis is much better solution, because in this case it is necessary only data about time and space of accident, on other words the important information is when accident occurred (hour, data, year) and where ( $\mathrm{km}$, section, road).

This kind of analysis may serve the road authority as a significant tool in decision making process. For them the main task is to make time between two consecutive traffic accidents on a road as long as possible. Also, this kind of model has potential for improving in the future.

Acknowledgements: This research is supported by Ministry of Education, Sciences and Technological Development of Republic of Serbia, project No. TR 36007 and this paper is one of results of PhD thesis on which author is working on.

\section{REFERENCES}

[1]. „Global status report on road safety 2013: Supporting a decade of action“, World Health Organization, Geneva, ISBN 978924156456 4, 2013.

[2]. , Global status report on road safety: time for action “, Geneva, World Health Organization, ISBN 978924156384 0, 2009.

[3]. T.F. GOLOB, W.W.RECKER:“Relationships among urban freeway accidents, traffic 
ROMANIAN JOURNAL

OF TRANSPORT INFRASTRUCTURE

Svetlana Bačkalić, Boško Matović, Anja Bašić

The time-space approach in the analysis of traffic safety on rural road

flow, weather, and lighting conditions", Journal of Transport 129 (4), 342-353, 2003.

[4]. E., HAUER: "On the estimation of the expected number of accidents", Accident Analysis and Prevention 18 (1), 1-12, 1986.

[5]. S. BAČKALIĆ: "Temporal analysis of the traffic accidents occurence in Province of Vojvodina", Transport Problems, International scientific journal, Volume 8, Issue 1, ISSN 1896-0596, 2013.

[6]. S. BAŠIĆ, T. BAČKALIĆ, D. JOVANOVIĆ: "Temporal and time series forecasting as a tool for traffic safety analysis", X International Symposium "ROAD ACCIDENTS PREVENTION 2010", Novi Sad, Serbia, ISBN 978-86-7892-279-4. 2010

[7]. M. ABDEL-ATY, A. PANDE: "Crash data analysis: collective vs. individual crash level approach”, Journal of Safety Research 38 (5), 581-587, 2007.

[8]. D. JOVANOVIĆ, T. BAČKALIĆ, S.BAŠIĆ: "The application of reliability models in traffic accident frequency analysis”, Safety Science 49, pp. 1246-1251, 2011.

[9]. D. LORD, F. MANNERING: "The statistical analysis of crash-frequency data: a review and assessment of methodological alternatives", Transportation Research Part A 44 (5), 291-305, 2010.

[10]. J. MARTIN: „Relationship between crash rate and hourly traffic flow on interurban motorways“, Accident Analysis and Prevention 34 (2002) 619-629, 2002.

[11]. X. QIN, J. IVAN, N. RAVISHANKER, et al.: "Bayesian estimation of hourly exposure functions by crash type and time of day", Accident Analysis and Prevention 38 (2006) 1071-1080, 2006.

[12]. A. ANDERSSON, L.CHAPMAN: „The use of a temporal analogue to predict future traffic accidents and winter road conditions in Sweden", Meteorological applications Meteorol. Appl. 18: 125-136 (2011), 2011.

[13]. J. EDWARDS: „The temporal distribution of road accidents in adverse weather",. Meteorol. Appl. 6, 59-68, 1999. 


\section{ROMANIAN JOURNAL \\ OF TRANSPORT INFRASTRUCTURE}

Svetlana Bačkalić, Boško Matović, Anja Bašić

The time-space approach in the analysis of traffic safety on rural road

[14]. A. SUKHAIA, A. JONESA, B. LOVEA, et al.: „Temporal variations in road traffic fatalities in South Africa“, Accident Analysis and Prevention 43 (2011) 421-428. 2011.

[15]. M. ABDEL-ATY, E.RADWAN: „Modeling traffic accident occurrence and involvement", Accident Analysis and Prevention 32 (2000) 633-642, 2000.

[16]. E. HAUER, et al.: „Screening the road network for sites with promise“. Transportation Research Record 1784, 27-32, 2002.

[17]. I.A. USHAKOV, R.A.HARRISON: “Handbook of Reliability Engineering”. John Wiley \& Sons, Inc., New York, USA, ISBN 0-471-57173-3, 1994.

[18]. B.S.DHILLON: "Reliability, Quality, and Safety for Engineers". Boca Raton, Florida, USA, ISBN 0-8493-3068-8, 2005.

[19]. H.PHAM: “Handbook of reliability engineering”, ISBN 1852334533. Springer, 2003.

[20]. S.BAČKALIĆ, D.JOVANOVIĆ, T.BAČKALIĆ: "Application of the reliability theory in the analysis of traffic safety on the rural road", Proceeding of the Multidisciplinary Academic Conference on Transport, Logistics and Information Technology 2013, ISBN 978-80-905442-2-2, Prague, 2013. 